\title{
VALOR SEMIOLOGICO DEL COLPOSCOPIO EN LA TOMA DE 1.650 BIOPSIAS CERVICALES
}

Doctor Gilberto Angel M. *

Tal vez no existe un procedimiento que presente opiniones y conceptos tan opuestos como lo que encontramos sobre el uso del colposcopio. Para unos ( $\mathrm{I}-2$ ) es un sistema anticuado y sin utilidad práctica, pero quienes se han ocupado del problema, publican sus experiencias expresando comentarios y estadísticas muy halagadoras. Olson y Nichols (3) inician su publicación con estas palabras: "Es difícil entender por qué ha sido tan duro convencer a los ginecólogos americanos del valor que tiene examinar el cervix bajo lentes de aumento. Un médico que omite tal examen, es similar al astrónomo que insiste en ver estrellas sin el uso del telescopio. Aunque esto es cierto, es solamente una fracción de la verdad".

\section{Material y métodos:}

En nuestro laboratorio particular, venimos usando desde el año de $195^{\circ}$ un colposcopio Philips, que nos permite observar el cuello uterino bajo Io y 40 aumentos. Previa embrocación con solución de ácido acético al $10 \%$ y solución concentrada de Lu- gol, hemos tomado las biopsias cervicales de los sitios electivos, a pacientes remitidas por los colegas. Durante este tiempo, hemos tomado r.650 biopsias cervicales y con la experiencia adquirida en el estudio colposcópico y correlación histológica de los cuellos analizados, nos permitimos exponer nuestro concepto sobre la cclposcopia en el estudio de la patología cervical.

\section{El colposcopio en las lesiones cervicales:}

Entre las publicaciones encontradas sobre el uso del colposcopio, en contramos la de M. Coppleson (4) quien scbre r.ooo colposcopias rutinarias verificadas en el Memorial Hospital de Sidney, diagnosticó directamente por la colposcopia 7 carcinomas. Uno fue verdaderamente in situ, otro de dudosa invasión y 5 presentaron ligeros cambios invasores. El mismo autor ancta, que en comparación con la citología simultánea de los casos mencionados, 3 presentaron citología positiva y los 4 restantes citologías falsas negativas. Las pacientes fueron some-

\footnotetext{
* Frofesor auxiliar de Histología, Departamento de Morfologia, Universidad del Valle.
} 
tidas a la biopsia, en vista de la imagen colposcópica. Anota el siguiente cuadro que resume la experiencia de otros autores: clínico, con todo su entusiasmo, se limita sólo a la colposcopia y descuida su complemento que es el estudio microscópico de lo que previamente

CARCiNomas Cervicales dianosticados por Colposcopia:

\begin{tabular}{lll}
\hline Salgado & $\mathrm{I}, 3 \%$ & (An. Bras Ginec. 27:339-I949) \\
Held & $0,73 \%$ & (Schwiz med. Wschr. 84:856-I954) \\
Hinselmann & $0,65 \%$ & (Personal comunication to Scheffey) \\
Kodolitsch & $0,60 \%$ & (Wien. Klin. Wschr. 32:572-I950) \\
Glatthar & $\mathrm{C}, 59 \%$ & (Oncología 5-I96-I952) \\
Wespi & $0,56 \%$ & (Bibliografía (5) \\
Leip & $0,41 \%$ & (Zbl. Gynag, 65:I.306-I94I) \\
Hohlbein & $0,41 \%$ & (Zbl. Gynak, 79:I.684-I957) \\
\hline
\end{tabular}

Navratil (citado por Coppleson) hace estudio conjunto de citología y colposcopia en I8.II2 pacientes, encontrando 306 casos de carcinomas incipientes del cervix. La colposcopia fue posiva en el $91 \%$ y la citología en el $88,5 \%$. La combinación de los dos sistemas, le dio una seguridad del $98,7 \%$. Di Poala (5) y colaboradores encontraron sobre 2.000 colposcopias verificadas, un $16 \%$ de fallas en la colposcopia y un $20 \%$ en la citología. La combinación de los dos procedimientos dio una seguridad del $96 \%$.

\section{Concepto sobre el colposcopio:}

Sobre la utilidad del colposcopio en la toma de las biopsias cervicales, encontramos conceptos opuestos y creemos que la base radica en que para comprender una imagen colposcópi$\mathrm{ca}$, es indispensable tener entrenamiento en la histología y patología microscópica cervical. Esto a veces es descuidado por el clínico y los patólogos rara vez toman biopsias. Si el observó "in vivo", no podrá captar el real valor del colposcopio e irremediablemente pasará al grupo de los escépticos y su aparato al sitio del olvido. Si insiste en observar al microscopio lo que inicialmente apreció con el colposcopio, en poco tiempo verá con satisfacción, que esta ayuda clínica le permite distinguir en sus pacientes los dos tipos de epitelio cervical. También observará glándulas, pequeños quistes purulentos, capilares normales, vascularización engrosada atípica, mosaicos difusos, hiperplasias vasculares, superposición de campos irregulares, leucoplasias, epitelio francamente atípico, pero lo más importante, cuadros vagos que no corresponden a los anteriores y que nos indica que algo ocurre en ese epitelio. Son pequeños campos punteados, con capilarización irregular, que posteriormente se comprobarán al microscopio como carcinomas in situ o metaplasias escamosas activas o epitelios activos con marcada inflamación, que requieren mayor atención clíni- 
ca. Según Limburg (4) de cada io imágenes de este tipo, una es carcinoma.

\section{Experiencia personal}

con el colposcopio:

De las r.65o biopsias cervicales que hemos tomado, bajo el control y dirección del colposcopio, encontramos 26 que corresponden a carminoma in situ, 220 carcinomas epidermoides, 4I4 casos de metaplasias escamosas con diferentes grados de actividad, 80 pólipos cervicales y 9 Io estados benignos que globalmente podemos agrupar como lesiones inflamatorias de diferentes tipos.

BIOPSIAS TOMADAS - 1.650

Lesiones inflamatorias benignas $910 \quad 55,8 \%$ Metaplasias escamosas benignas $414 \quad 25.09 \%$ Carcinomas epidermoides $\quad 220 \quad 13,3 \%$ Pólipos cervicales

Carcinomas in situ

Todas las biopsias han sido acompañadas de estudio citológico y no siempre hemos encontrado una estricta correlación entre el Papanicolau y la histología. Citologías diagnosticadas como sespechosas tipo III han sido en la biopsia carcinomas, y otras veces citologías positivas nos han inducido a repetir tomas de biopsias, que posteriormente han comprobado el diagnóstico citológico.

La fuente luminosa del colposcopio la hemos usado rutinariamente en la toma de biopsias de endometrio, exudados vaginales y citologías, aprovechando mirar rápidamente el cuello con el colposcopio, costumbre que nos permitió diagnosticar 3 carcinomas in situ, en pacientes, sin sintomatología clínica, no sospechadas por el médico remitente y que por su objetividad nos permitimos resumir a continuación:

BIOPSIA No 87I4. Noviembre. ig6o. Paciente de 38 años, remitida para exudado vaginal. Presentaba imagen colposcópica atípica en su labio anterior. El estudio citológico fue positivo. Se le informó al colega el exudado solicitado, positivo para monilias y posteriormente se le comentó la impresión colposcópica y el resultado citológico. Fue remitida nuevamente para toma de biopsia cuyo resultado fue de carcinoma in situ (fig. I) cuadro que persistió en el

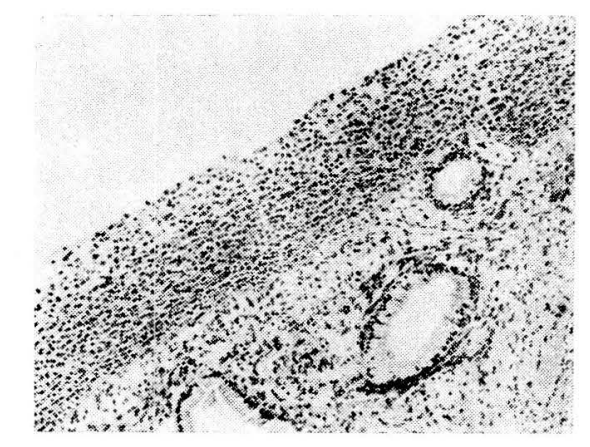

Figura 1. Capa basal hiporpásica, polaridad invertida de sus elementos, indiferenciasión celular y mitosis sunericiales.

análisis correspondiente a conificación cervical.

BIOPSIA No 9867. Abril. rg6r. Paciente de $z 0$ años, esterilidad primaria, remitida para estudio citológico de Shorr, por irregularidad en el ci- 
clo y amenorrea. Cuadro colcoscópico de mosaico en comisura derecha. Citología tipo IV. La paciente fue remitida nuevamente para toma de biopsia, cuyo diagnóstico fue de Carcinoma in situ (fig 2) pero posteriormente en el estudio cervical, se comprobaron pequeños brotes invdsivos.

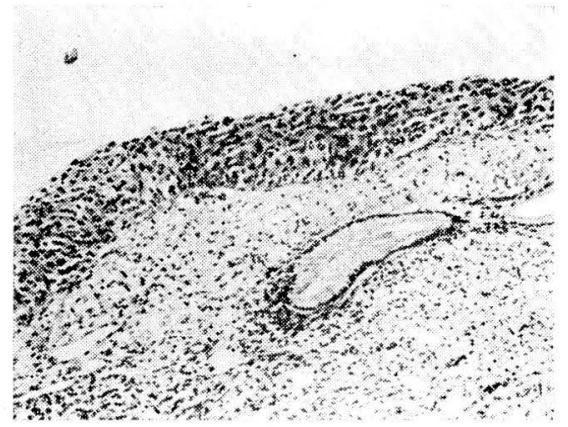

Figura 2. Marcada indiferenciación celular con mitosis superficiales.

BIOPSIA No 63-20I. Abril. 1963. Paciente dé 42 años, remitida para estudio citológico por sinusorragias esporádicas. Al colposcopio, presentaba tres pequeños puntos, el mayor de 4 $\mathrm{mm}$. con zonas de campos superpuestos y capilares de calibre irregular. La citología fue reportada como tipo III sospechosa y la paciente fue remitida nuevamente para toma de biopsia. La biopsia correspondió a un carcinoma in situ (fig. 3) con zonas limítrofes normales, diagnóstico que persistió en una sola preparación, de cortes seriados de todo el cuello remitido. (Reporte M63-2376. Facultad de Medicina. U. del Valle. Mayo Ig63). En la histerectomía total posterior, no se encontró alteración neo- plásica alguna. (Reporte Facultad de Medicina. Julio 5, I963. M-63-2844).

\section{Comentario:}

Basados en nuestra experiencia y trabajos consultados $(6,7,8,9$, Iо, II, I2, I3, I4, I5, I6, I7, I8, I9, 20, 2I $, 22,23,24,25,216,27,28,29,30$ ) el colposcopic presenta las siguientes ventajas:

I? Permite descartar la toma de biopsias inútiles, en pacientes que clínicamente parecen indispensables, como en los casos de ectropiones papilares puros, donde la imagen colposcópica es nítida y sin alteraciones especiales.

2? En la toma de biopsia, permite seleccicnar los campos francamente benignos de epitelio cilíndrico, de los

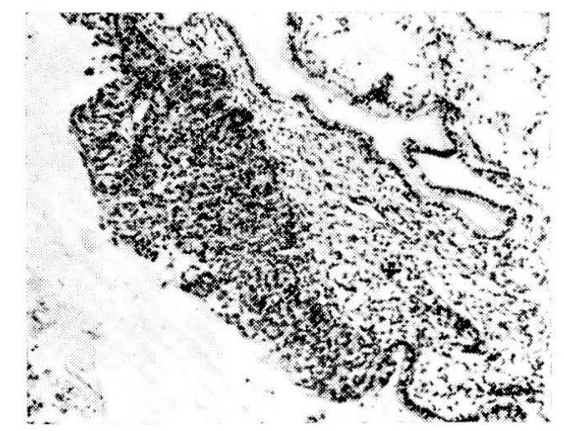

Figura 3. Bordes endocervicales normales con con proliferación vegetante, de elementos indiferenciados, numerosas mitosis intermedias $y$ superficiales.

erosivos capilarizados, muy frecuentemente correspondientes a inflamaciones con discretas actividades epiteliales, como también los campos de actividad epitelial correspondientes a 
metaplasias activas o carcinomas preinvasivos.

3. Una biopsia tomada de diferentes partes y que por casualidad no tome los sitios de actividad celular o carcinomas incipientes, debe ser considerada como una FALSA BIOPSIA, evitable con el colposcopio, pues con alguna práctica es casi imposible que en un epitelio atípico se le pase al colposcopista.

$4^{0}$ El colposcopio solo, a pesar de presentar imágenes propias de carcinoma, no es suficiente para hacer diagnóstico de proceso neoplásico y siempre se debe comprobar su diagnóstico con el estudio histológico. Se debe considerar como una valiosa ayuda, nunca se puede afirmar categóricamente la malignidad, pues procesos de sífilis, T.B.C. o metaplasias escamosas muy activas, dan imágenes muy atípicas. Se debe considerar, que su uso, junto con la citología y el test de Schiller, orientador del colposcopio, nos dan en el momento actual el máximo de seguridad en el diagnóstico del carcinoma cervical en su estado inicial o pre-invasivo.

\section{Resumen:}

Se hace un comentario sobre la ayuda que ha prestado el colposcopio en la toma de r.65o biopsias cervicales, en clientela particular, en el transcurso de I3 años. Se hacen consideiaciones sobre experiencias de autores que se han ocupado del tema. Se emite un concepto personal sobre el colposcopio, recalcando, que la base de conceptos opuestos sobre su utilidad, radica en que para distinguir la imagen colposcópica, es preciso estar muy familiarizado con la patología microscópica. Se relata la experiencia personal de tres pacientes con carcinoma in situ, asintomáticas, no sospechadas por los colegas, que tuvieron su diagnóstico precoz gracias a la imagen colposcópica que indujo à la comprobación, por medio de la biopsia. Se comparte la opinión de quienes se han ocupado del tema, que el colpcscopio junto con la citología, el test de Schiller y el estudio histológico, son hoy en día, los pilares básicos que nos dan el máximo de seguridad en el diagnóstico precoz del carcinoma en su estado pre-invasivo.

\section{BIBLIOGRAFIA}

1. NOVAK E. and NOVAK: Gynecologic and Obstetric Pathology. W. B. Saund. Co, 1949,

2. E. NOVAK and D. WOODRUFF: Gynecologic and obstetric Pathology. W. B. Saund. Co. 1962.

3. OLSON A. W. NICHOLS E. E.: Colposcopic examination in a combined approach to cervix diagnosis and prevention of carcinoma of the cervix. Obst Gynec. N. Y. 15:372. 1960.

4. COPfLESON M.: The value of colposcopie in the detection of preclinical carcinoma of the cervix. J. Obst. Gyn. of Brit. Empire 67:11 1960.

5. DI PAOLA G.: Comentario sobre 2.000 colposcopias. Bol. Soc. Obst. Gyn. 3i:140. 1958. 
6. BIBIloni P.: A propósito de la colposcopia. Bol. Soc. Arg. Ciruj. 11:336. 1948.

7. Bibiloni P.: La colposcopia. Rev. Pat. Fem. Hosp. Rivad. 4:12. 1950.

8. DI PAOlA G.: Diagnóstico de lesiones cervicales. Rev. Med. Pat. Fem. 17:3. 1941.

9. HINSELmANN H.: Introduction a la colposcopie. Edit. A. Keding, Ginebra, 1938.

10. HINSElmanN H.: Diagnóstico de los estados precursores del carcinoma del cérvix. Rev. Med. de Córdoba 40:12. 1952.

11. WESFI H.: Farly carcinoma of the uterine cervix. Grune and St. New York, 1949.

12. SCHEFFEY L. C., BOLTEN K. A. and LANG W. R.: Colposcopie in cancer diagnosis. Dist. and Gynec. $5: 294.1955$.

13. SCOTT R. and REAGAN J. W.: Diagnoctic cervical biopsy, technique for the study of early cancer. J. A. M. A. 160:343, 1956.

14. Antoine T.: Early diagnosis of cancer of the cervix. Am. J. Obst. and Gyn. 68: 466. 1954.

15. AHUMAdA J. C. y Colab.: El cáncer ginecológico. Edit. El Ateneo, Bs. As., 1953.

16. Albertelli J. y TERzano C.: Diagnóstico oportuno del cáncer del cuel’o uterino. Pres. Méd. Arg. 39:795. 1952.

17. ARENAS N.-FOIX-BELLO-DAVIDSON: Correlación entre la colposcopia y la histopatologia en las cerviconatias crónicas. Obst. y Gynec. Lat. Amer. 18:532. 1960.

18. BIBILONI P.: La colposcopia en el diagnóstico y profilaxis del cáncer cervical. Edit. Universitaria, Bs. As., 1956.

19. DI PAOlA G.: Pesquisa de los estados iniciales del carcinoma cervical. Rev. Col. O!st. y Ginec. 14:13, 1963.

20. DI PAOLA G.: SANMMARTINO R., ARRIGHI L., VASeUEz E., TERzANO G.: Epitelio atípico no invasor; nomenclatura, patología, diagnóstico y tratamiento. Obst. Ginec. Latin. Améric. 19:223. 1961.

21. GERLI M., BERLINGIERI D.: The combined use of colpocitology and colpscopie in the early diagnosis of cancer uterine cervix. Minerva Ginec. 14:539, Italy, 1952.

22. GUZMAN L., CUDEMUS L.: Comentarios sobre nuestras primeras 1.000 colposcopias. Rev. Obst, y Ginec. (Caracas) 21:113. 1961.

23. GRIEFAHN S.: Les colposcopes en gynécologie. Rev. Fr. Gynec. et obst., mayo 1960.

24. HinselmanN H.: Los progresos actuales de las colposcopia. Sem. Med. 50:747. 1954.

25. HILSELMANN H.: La profilaxia del cáncer cervical mediante la colposcopia. El Día Méd. 26:785. 1954.

26. KELLER R., KELLER B.: L'intérêt de l'examen colposcopique en gynecologie. La Sem. des Hồ., 37 aneé, 66:67. 1961.

27. ROGANTI A.: Colposcopia y diatermo-coagulación en las cervicitis. Edit. El Ateneo, Bs. As., 1944.

28. HINSELMANN H.: Methods of modern colposcopy in diagnosis of carcinoma of the cervix. An. Bras. Ginec. 48:189, 1959.

29. Mestwerdt G.: Atlas de colposcopie. Edit. Masson et Cie., París, 1955.

30. SIRTORI C., MORANO E.: Il cancro nell' utero, dalla macroscopia all'ultrastructura. Edit. Casa Ambrosiana, Milán, 1960. 